\title{
INTERVENCIÓN Y REGENERACIÓN DEL ESPACIO PÚBLICO Y POLIITICAS PATRIMONIALES: EL CASO DEL PARQUE DE PÍNTAG
}

\section{INTERVENTION AND REGENERATION OF THE PUBLIC AREA AND PATRIMONIAL POLICIES: THE CASE OF PÍNTAG PARK}

FRANTZ JARAMILLO ${ }^{1}$

Recibido: 31 de enero de 2017 Aceptado: 6 de marzo de 2017

\footnotetext{
${ }^{1}$ Docente de la Pontificia Universidad Católica del Ecuador, Facultad de Comunicación, Lingüística y Literatura, Escuela de Comunicación, Quito, Ecuador (fjaramillo438@puce.edu.ec).
} 



\section{INTERVENCIÓN Y REGENERACIÓN DEL ESPACIO PÚBLICO Y POLIITICAS PATRIMONIALES: EL CASO DEL PARQUE DE PÍNTAG}

\section{INTERVENTION AND REGENERATION OF THE PUBLIC AREA AND PATRIMONIAL POLICIES: THE CASE OF PÍNTAG PARK}

FRANTZ JARAMILLO

PALABRAS CLAVE: espacio público, regeneración urbana, patrimonio, ciudad, ciudadanía, comunicación, representación, memoria.

KEY WORDS: public space, urban regeneration, heritage, city, citizenship, communication, representation, memory

\section{RESUMEN}

Las intervenciones de rescate patrimonial y organización de los espacios públicos, en el caso del objeto de este artículo, el parque, plantean un campo de disputa entre las políticas de patrimonio y los usos concretos de la población. La controversia se centra en la escasa o casi nula participación de la ciudadanía en la planificación y ejecución de los proyectos de rescate, que terminan sobreescribiendo la memoria, las prácticas y los usos que le dan las personas simbólica, cultural y espacialmente. Los lugares (re)organizados y (re)escritos terminan constituyéndose en sitios de espectáculo y tránsito que ya nada tienen que ver con lo que una vez fueron: el núcleo de encuentro e intercambio sociocultu- 
ral. Palimpsesto que termina constituyéndose en la única forma de entender los centros y las periferias históricas de los centros poblados más importantes como la ciudad de Quito.

\section{ABSTRACT}

The heritage rescue and the organization of public spaces -in the case of this article, the park- raise a dispute between heritage polices and the uses of areas that are given by the people. The controversy focuses on the poor or almost null citizen participation during the planning and execution of rescue projects. These projects end up by over-writing memory, practices and uses that people assign to the park symboli- cally, culturally and spatially.

The (re) organized and (re) written places end up as points of spectacle and transit that have nothing to do with what they once were: the nucleus of encounter and sociocultural exchange. This palimpsest establishes as the only way to understand the history of the most populous and important towns such as Quito city.

\section{METODOLOGíA}

Para la elaboración del artículo se hizo una revisión de la literatura sobre el tema del espacio público, los usos sociales y simbólicos, y lo concerniente a ciudad y ciudadanía.

Se realizó un trabajo de campo, observación y sistematización de datos a partir de entrevistas a pobladores de la parroquia de Píntag, usuarios concretos del parque; además se efectuaron búsqueda de archivos fotográficos y captura de imágenes actuales del espacio mencionado, para establecer una comparación entre la memoria oral y visual con la propuesta de configuración después de la intervención. 


\section{DISCUSIÓN Y ANÁLISIS}

El estado actual de la ciudad, como señala Debord (2003), conlleva una fuerte noción de la cultura del espectáculo, donde el espacio toma la forma final de la reificación mercanti;; los cambios, los "rescates" producto de las políticas de salvamento y conservación del patrimonio, tienen un profundo sentido en la espectacularización y mercantilización con fines turísticos, sobre todo, en cuanto a los centros históricos en las ciudades de América Latina se refiere. En el caso de Quito, por ejemplo, las políticas patrimoniales se basan, fundamentalmente en decisiones de interlocutores "legítimos" e institucionales que intentan sustentar y difundir una cultura del patrimonio para reactivar cultural y económicamente al territorio y a la población directamente involucrada (Kingman 2004).

Políticas de patrimonio que intentan volver funcional a la población (Foucault, 1996) dentro del sistema inmerso en un fuerte proceso de desterritorialización y deshistorización de los sujetos. Los lugares públicos o de encuentro como plazas, calles, pasajes, jardines, van tomando forma de espectáculo, y dejando atrás su carácter histórico, de encuentro o de confrontación. Espacios que se conforman a manera de imágenes dialécticas (Benjamin, 2005) que van borrando o desechando lo que a la ciudad moderna no le sirve y re-semantizando al coleccionista -turista- lo nuevo que se escribe sobre el mapa urbano de lo que alguna vez fue (Ilg. 2017)

\begin{abstract}
"Las imágenes dialécticas son constelaciones entre las cosas alienadas y la significación exhaustiva, detenidas en el momento de la indiferencia de muerte y significación". Por un lado, significa que las cosas que comprenden estas constelaciones se han extraído de su contexto, del cual, de cierta manera, ya estaban excluidas, ya que, como desechos, fueron despojados por la ciudad, y, por el otro, quiere decir que se hallan alienadas entre sí en esta nueva y sorprendente yuxtaposición en el escaparate del coleccionista." (Ilg, 2017: 159)
\end{abstract}

Transformación ambivalente que se convierte en monopolio de las apariencias en donde lo que aparece es bueno y lo bueno es lo que aparece a manera de espectáculo (Debord, 2003). El parque como espacio recuperado, se plasma en forma de orden, de modelo similar y repetitivo en las varias parroquias de Quito. Las intervenciones se han desplazado del centro histórico tradicional de la ciudad hacia las parroquias rurales creando nuevos centros en las periferias 
de la urbe. Estos modelos no han sido consensuados ni ha existido la participación de los pobladores. Las intervenciones responden a contratos y fechas específicas, más que a necesidades de intercambio simbólico, social o histórico donde entran en discusión el sentido político, cultural y simbólico (Bourdieu, 1991) confrontando la memoria social e histórica con la "industria del turismo y el negocio inmobiliario" (Kingman 2004).

Pero cabe preguntarse quiénes son parte de las decisiones o, quiénes son dueños de esa hegemonía simbólica que acumula poder desde las instituciones autorizadas a ejercer esas políticas. Como describe Cueva (2010) en cuestionamiento a lo expuesto en las políticas del rescate de lo público ejecutadas en el Plan General de Desarrollo Territorial de 2001:

....algunos comportamientos ciudadanos... desconocen la historia y elvalor de los equipamientos urbanos. Para el efecto es necesario a través del fortalecimiento de la ciudadanía consolidar una sólida lógica de cultura patrimonial de la ciudad que revalorice el uso de la ciudad y complemente una propuesta técnico-funcional de recuperación y ampliación de los espacios públicos. (PGDT 2006:10 en Cueva, 2010:104)
Estas políticas de patrimonio responden a un proceso de separación de las relaciones sociales y de las prácticas populares que apuntan a reorganizar los lugares como espectáculo y nostalgia, tendientes a la comercialización especialmente turística y mercantil de los espacios públicos (Gorelink: 1998) donde se intenta reinventar o reescribir la identidad desde políticas que responden a intereses netamente esquematizados en términos de rentabilidad y reactivación económica (Sierra, 2016) de los territorios y las poblaciones.

Los lugares intervenidos alcanzan un nuevo orden y cambian desde perspectivas de planificación de lo patrimonial entendidas desde el "discurso que ve a la sociedad como objeto de intervención" (Maluf: 1990) para responder a políticas que (re)construyen o (re) escriben lenguajes, signos y símbolos a través de versiones oficiales del ornato y la ciudad sin tomar en cuenta las representaciones o apropiaciones que se tejen o tejieron en esos espacios públicos.

La apropiación puede generarse en dos sentidos; la acción de transformación y la identificación simbólica. La primera enlaza la territorialidad y el espacio personal y la segunda la identificación simbólica en la que se manifiestan procesos, afectivos, cognitivos e interactivos." (Vidal \& Pol, 
2005). En síntesis, solo en una estructura apropiada de espacios públicos se halla el complemento ideal del sentido individual del habitar." (Ospina y Tascón, 2012: s/p).

La nueva organización planteada en forma de rescate o de regeneración adopta modelos y sistemas que acentúan la conformación del espacio como espectáculo, en palabras de Clara Páez, una de las usuarias: "el parque (de Píntag) me sirve solo para ver". El parque ya no es un espacio en donde se intercambian relaciones sociales y prácticas cotidianas sino que se ha llegado a convertir en espectáculo con tendencia a visualizar. Espectáculo con una vida social delineada hacia un "orden urbano" predeterminado, prediseñado y banalizado y que lo podemos encontrar repetido y diseñado en las demás parroquias, no solo de Quito sino de toda la República.

"la producción capitalista ha unificado el espacio, que ya no está limitado por sociedades exteriores. Esta unificación es a la vez un espacio extensivo e intensivo de banalización. La acumulación de mercancías producidas en serie para el espacio abstracto del mercado [...] esa fuerza de homogenización es la artillería pesada que ha derribado todas las murallas chinas." (Debord 1998: 50)

"La vista es el sentido humano privilegiado. El espectáculo se constituye allí donde hay representación" (Debord: 2003) y esta representación intenta construir una imagen nostálgica y ordenada de un mundo que no existió sino que pasa a sobreponerse como la memoria oficial de un espacio que intenta un orden y una escenificación con lineamientos para reactivar la movilidad, sobre todo, turística de lo urbano/rural, en la "Colonial ciudad de Quito" y que va dejando de lado ese derecho a la ciudad (Perry, 2016) a "ese espacio público -la calle, la plaza, el parque- donde expresa y se exige más". 


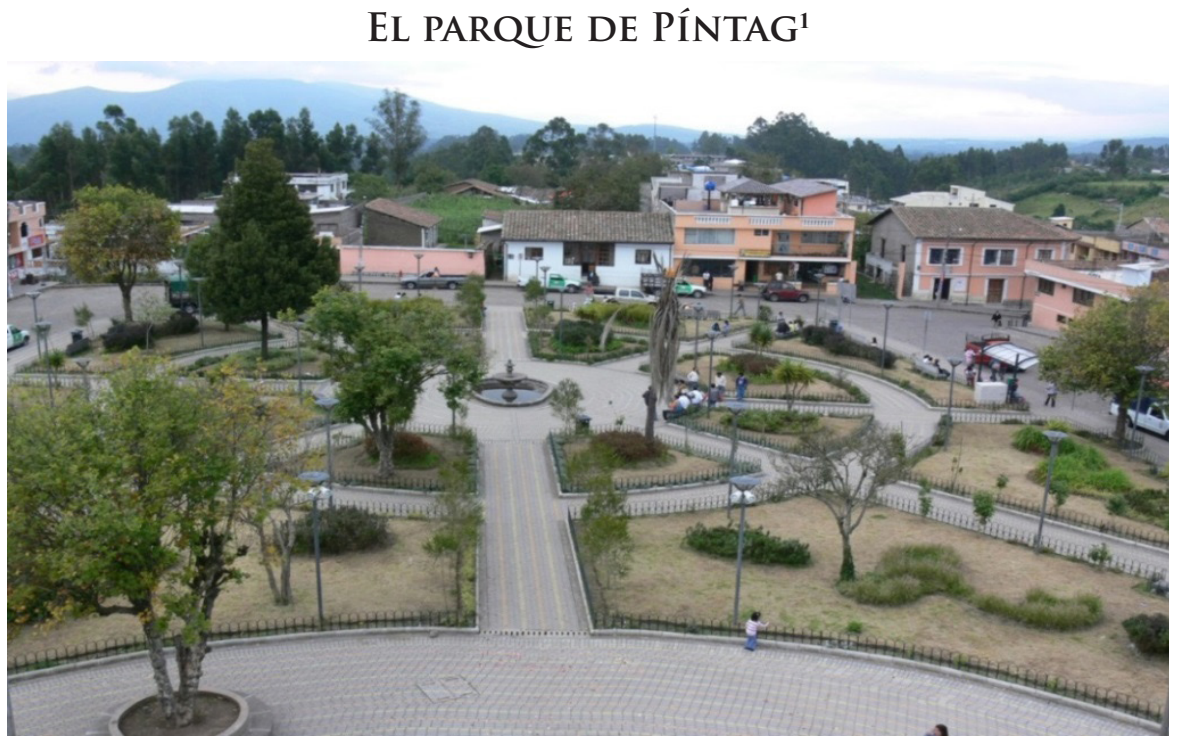

Fig.1. Forma actual del Parque de Píntag, después de la intervención del FONSAL en el Año 2006. Vista desde el campanario de la iglesia (fotografía: Frantz Jaramillo).

Las flores y los jardines, los pasajes con adoquín, la pileta y su eje central, las bancas y las lámparas que iluminan en la noche el lugar son la imagen de la versión creada luego de las varias intervenciones desarrolladas ornamentalmente, en un inicio, por parte del municipio (1987) y la última, como política patrimonial, del Fondo de Salvamento², FONSAL (2006) se contraponen a la memoria oral de lo que

${ }^{1}$ La Parroquia Píntag está ubicada a 40 kilómetros al sur de Quito, cerca del Valle de los Chillos. Esta zona se caracteriza por la presencia del volcán Antisana y por ser una tierra de páramo, de ahí que posee múltiples arroyos y es productora de agua. En la época precolombina, el cacique y héroe nacional, el general Píntag, conocido como el primer "guerrillero ecuatoriano", escogió esta zona como la base de resistencia a la invasión inca, especialmente a los ataques de Huayna Cápac. El nombre de esta zona se determinó en honor al líder quiteño, quien desarrolló una estrategia con la que combatió a los incas por cerca de 12 años. Durante la Colonia, la orden dominica inició la evangelización de estos territorios, de allí que la patrona de este territorio es la Virgen del Rosario. En 1856, el entonces presidente de la República, Gabriel García Moreno, declaró a Píntag como una parroquia. https://sites.google.com/a/parroquiaruralpintag. gob.ec/parroquia-rura/home/nh5 Acceso noviembre de 2016

${ }^{2}$ El fondo de Salvamento de Patrimonio Cultural fue creado mediante la Ley de Creación del Fondo de Salvamento de patrimonio Cultural (Ley No.82) por el Congreso Nacional y publicada en el Registro Oficial mediante decretos: 1.- Decreto 686-A (Suplemento del Registro Oficial 213, 16-VI-89) 2.- Decreto 726 
recuerdan fue la plaza -en la primera mitad del siglo XX-y luego el primer parque de Píntag -desde los años 60- María Maldonado Cedeño de 75 años y Clara Páez de 60 años, habitantes de la parroquia y moradoras cercanas al Parque.

Rex Sosa, historiador y habitante de Píntag, narra que no se ha determinado con precisión cuándo se crea la plaza porque no hay una fecha exacta de la fundación de Píntag. En las actas del cabildo aún no ha sido posible identificar el nacimiento exacto de la parroquia, de la iglesia y de la plaza del pueblo. Pero los primeros datos históricos y poblacionales vienen desde inicios de la colonia:

Juana, india de Píntag, acusó antes de 1643, al español Pedro Vaz de San Payo, mercader, de haber procreado un hijo con él, pero este al testar el 23 de febrero de 1643, declaró que no era verdad. (Noboa, 1986: 127 y Sosa, 2011: 88).

La estructuración de las parroquias deviene de los curatos que fueron conformados cerca de las grandes zonas de hacienda. En el caso de Píntag, en el siglo XVI, las haciendas cercanas de importancia son las pertenecientes a conventos como San Agustín, La Merced y de La Compañía de Jesús, y luego, en el siglo XX, pasarían a ser propiedad de la Junta de Beneficencia. Alrededor de los 20 y 30 del siglo pasado se puede determinar la presencia de la iglesia y la plaza como lugar de importancia. Son escasas las imágenes de aquella época ya que muy pocas personas del pueblo tenían acceso a la fotografía.

En el caso observado: el parque (urbano/rural) de Píntag, (que es un centro periférico de una parroquia quiteña a 40 kilómetros de la capital) el FONSAL intervino sobre ese espacio público y los pobladores tomaron distintas actitudes, en primer lugar la intervención se implementó de sorpresa, en el año 2006 -como el inicio de un espectáculo-: debía estar presente el telón de fondo, según cuenta Clara Páez en la entrevista concedida:

"- No nos dejaron ver, todo era tapado [... . era una tela verde y luego que

(Registro Oficial 231, 12-VII-89). En este contexto la Ley de creación parte considerando: Que la ciudad de Quito constituye "Patrimonio Cultural de la Humanidad"; Que el terremoto de marzo afectó la estructura de algunas edificaciones que forman parte de ese Patrimonio Cultural; Que es imprescindible proteger, conservar y restaurar los bienes culturales que pertenecen a la nación; y, Que mediante Ley No. 136, se creó el Fondo de Emergencias Nacionales, para atender desastres que ocasionan la destrucción de obras públicas de carácter nacional y local. El FONSAL era dirigido por el Alcalde de la ciudad de Quito, por un delegado del Instituto Nacional de Patrimonio y un delegado de la Casa de la Cultura Ecuatoriana. En el 2010 pasaría a llamarse Instituto Metropolitano de Patrimonio. 
ya estaba, ahí quitaron.

- ¿Y por qué cree que no les dejaron ver?

- Es por que hicieron al capricho de ellos"

Estas palabras de Clara Páez de 67 años de edad, quien vive frente a una de las esquinas del parque, plasman la actitud de las políticas patrimoniales de turno. Había que cumplir un cronograma y había que responder a un presupuesto.

No olvidemos, sin embargo, que se desarrolla al mismo tiempo una lucha, muchas veces invisible e invisibilizada, por los usos de los espacios o por el "descentramiento de la tradición y la memoria" que responde al desarrollo de identidades distintas a las de la cultura institucional (Kingman, 2004: 64).

Detrás de ese gran telón verde el único que tenía acceso a una mirada parcial de lo que se hacía tras bastidores era Vicente Gutiérrez, cura de la parroquia, quien activó la voz de alarma. - "Iban a desarmar, iban a quitar la grada pero antes el padre impidió, sino se iban a llevar todo" dice María Maldonado Cedeño de 75 años, quien ha vivido toda su vida frente al parque. Ella fue una de las varias personas que no permitieron que el pretil de la iglesia sea desarmado para que tome una forma circular con graderíos de esquina a esquina.

- Ya habían estado quitando las piedras [...] esto, diga usted, cuántos años que tendrá porque esto mi mamá conversaba que ha sido cuando ella ha sido pequeña" (Clara Páez, entrevista).

Quizá esta fue la única participación de la comunidad en esa regeneración del parque. Los habitantes, muy apegados a la religiosidad y con una marcada identificación con la edificación de la iglesia como eje central, fueron más allá de esa cultura institucional para defender un espacio que estaba mucho más arraigado en su sentido práctico (Bourdieu, 1991), en el uso físico y simbólico de la iglesia, que en la noción "patrimonial" de embellecimiento y regeneración de las fachadas. Colectivo que marcó la diferencia entre las intervenciones patrimoniales y los usos concretos y prácticos de las personas. De los intercambios de relaciones sociales que se tejen en esos espacios.

Una vez alzado el telón el espectáculo comenzó, pero, para los parroquianos el parque ya no es el mismo. Sobre todo, no sienten ese espacio como propio, como sitio de encuentro o de intercambio. 

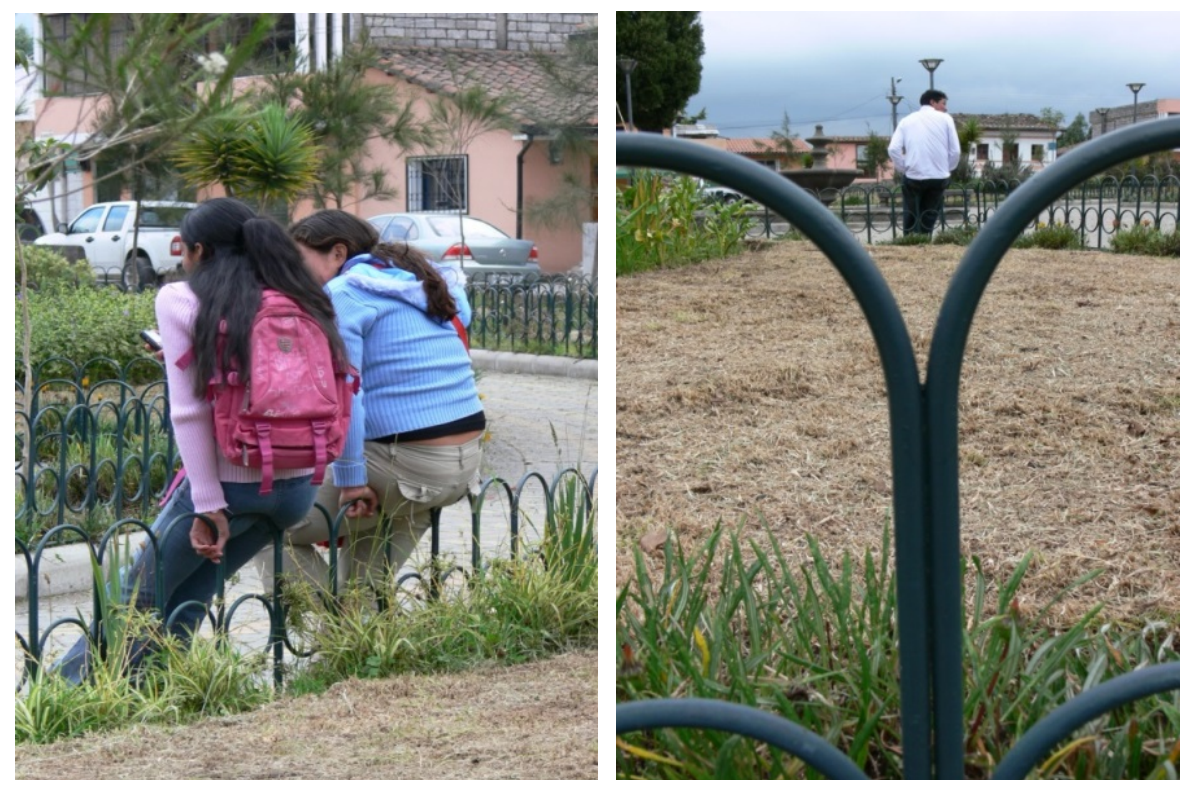

Fig. 2 y 3. Imágenes del parque intervenido con la regeneración del Fonsal (fotografía: Frantz Jaramillo).

La política de intervención no contempló la voz de los usuarios directos y ejecutó el rescate o regeneración que implica instalaciones luminosas, disposición del espacio con jardines enrejados y segmentados por calles pequeñas, una pileta central y bancas para pocas personas.

Según la narración de María Maldonado Cedeño, primero existió una plaza donde se desarrollaban múltiples actividades: la principal el acceso a la iglesia, pero también los festejos de santos y festividades del pueblo, toros y deportes. Con la regeneración realizada por el Fondo de Salvamento, los usos del parque cambiaron y este espacio dejo de ser parte del ornato que "adornaba la iglesia" (Clara Páez) y que a la vez servía "para que descanse la gente que venía de las haciendas y debía ir hacia sus hogares".

-Cuando yo era niña, la plaza era sin nada, sin árboles sin nada [...] y aquí, en esta plaza jugaban la pelota de tabla y el fútbol. (María Maldonado)

Clara Páez, cita, como principal actividad social de la plaza la misa que a inicios del siglo XX aún se realizaban afuera de la iglesia, para ella lo más importante es el templo, hecho que coinci- 
de con María Maldonado, el centro de las relaciones sociales confluía en la iglesia y la religiosidad. Las fiestas y los Toros de pueblo tenían relación con fechas religiosas y la fundación de la parroquia con nombre igualmente religioso: "San Gerónimo de Píntag".

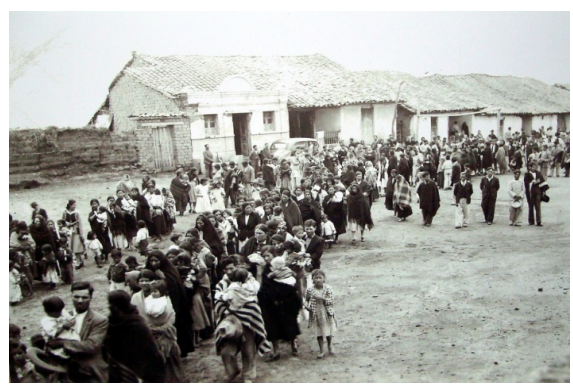

Fig.4. Desfile de fiestas, (tomada en los años 40 aprox.). La primera edificación de arriba a la derecha es el casa de la señora María Maldonado. Foto proporcionada por Manuel García, archivo particular.

Pero las relaciones sociales que se desarrollaban en la plaza, no eran únicamente eucarísticas: también, la misma plaza, era cancha de fútbol, sitio de intercambio de productos y ventas pequeñas de comida. Y en los años 50 fueron escenario de los levantamientos por tierras en las haciendas cercanas, desde la más famosa, la Hacienda la Merced, hasta las tomas de tierras de lo que hoy es las Comuna "4 de Octubre" en el sector de la hacienda de Valencia.
- Venían de todas partes, de todos los pueblos... las bandas que venían de Alangasí, de Sangolquí, la banda de aquí, la banda de Amaguaña, de todos lados venía la banda. Y venía la gente y se llenaba y aquí en nuestra casa se recibía una banda. (María Maldona

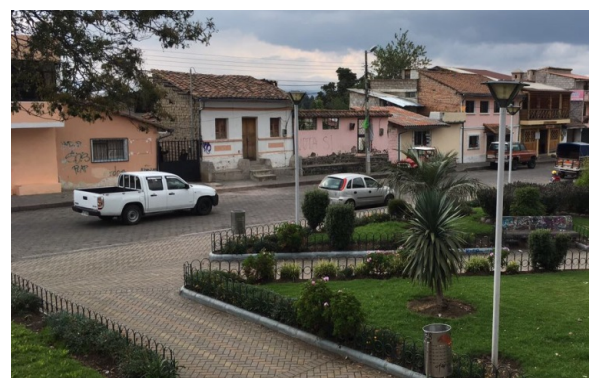

Fig. 5. Vista actual de la casa de María Maldonado quien cuenta que con la intervención, únicamente fue pintada la fachada. (foto: Frantz Jaramillo).

Manuel García, acuarelista, fotógrafo y habitante de Píntag lleva registro de varios acontecimientos de la parroquia, él cuenta que "hasta los años 40 en las fiestas del Corpus Cristi, aun se realizaba la toma del pretil, por parte de pobladores de Yurac, los cuales venían vestidos de militares, pero esta práctica dejó paulatinamente de realizarse, sobre todo, a partir de 1953, fecha en la que se construyó el primer parque. 


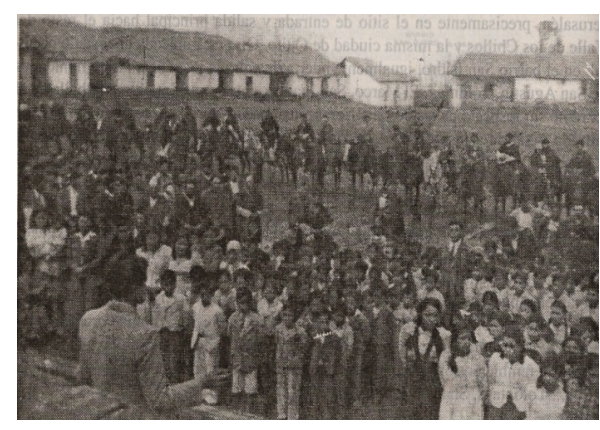

Fig. 6. Evento público, impreso en los años 50 del siglo pasado aprox. (Archivo de Manuel García).

Clara Páez, la fotógrafa de retratos casi oficial del pueblo y que vive en la esquina norte del parque, cuenta que se deshizo de todos los negativos que realizó de las fiestas, de familias y retratos que eran comisionados por diversas personas. Un tiempo vendía las fotos como "recuerdos" pero como la gente ya dejó de comprarlas, ya botó todo a la basura. Sus memorias sobre el parque también son las fiestas y los toros. Pero lo que más

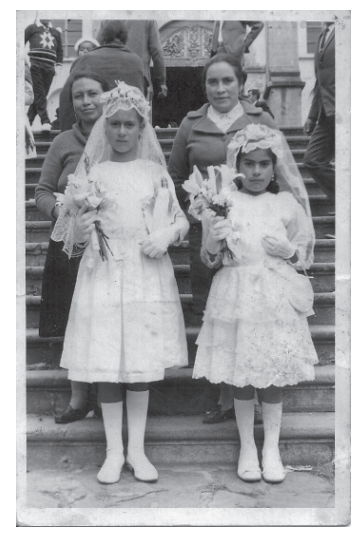

Fig. 8. Primera comunión de las primas Santillán, foto tomada en los años 60 del siglo pasado. (Archivo familia Santillán).

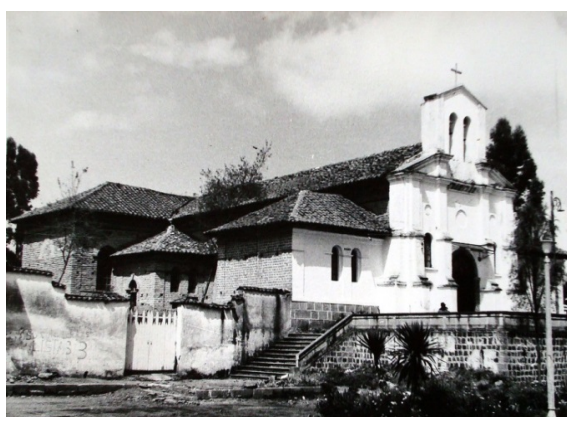

Fig. 7. Vista antigua de la fachada y pretil de la iglesia (Fotografía: Manuel García).

recuerda es la relación que tenía con la misa y con su familia, para ella el parque de antes era mejor porque tenía mejores jardines, porque "adornaban la iglesia".

- Era bien bonito antiguamente pero hoy es puro palos como monte, no hay gracia de parque (...) a nosotros de aquí del parque no nos gusta". (Clara Páez).

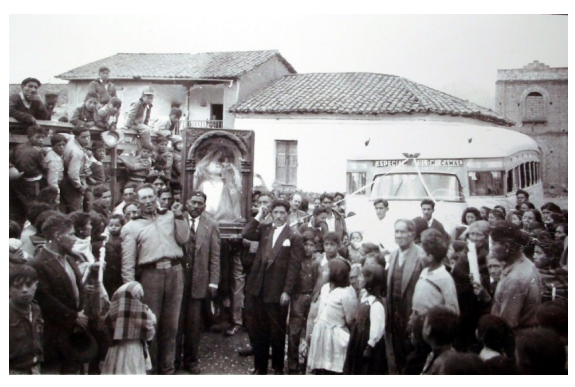

Fig. 9. Evento religioso, 1960 aproximadamente (Archivo Manuel García). 
Clara cuenta que las misas y los bautismos eran acompañados por bandas de pueblo, y procesiones, incluso se paseaba con "San Gerónimo" el santo del pueblo. La banda entraba por las calles amplias de la plaza, distintas a los múltiples y angostos pasadizos que han ordenado a las actuales procesiones, que hoy ingresen por la calle oriental del parque.

Las misas y procesiones ya no pasan por la parte frontal del pretil sino que toman la calle oriental para ingresar a la iglesia, de igual forma la salida de la procesión y los asistentes a misa se la realiza por la misma calle. Esta situación, por ejemplo, marca la pauta de un cambio en los usos de ese espacio.

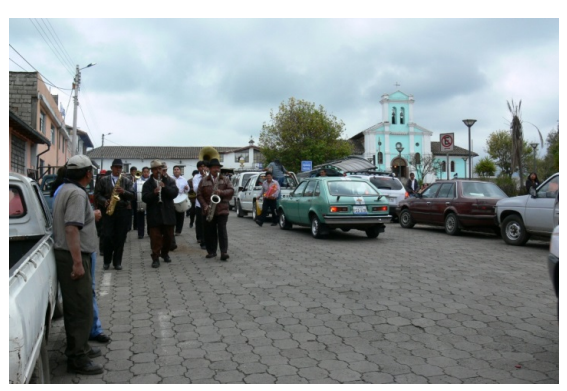

Fig. 10. Banda de Pueblo, años 40050 aprox. (Archivo Manuel García).

A Clara no le gustan las plantas ni los árboles que puso el FONSAL como parte de la recuperación del parque, ella, afirma que ya no utiliza el espacio, que solo le sirve "para ver". Estos sitios se han convertido en sitos de admiración, de visualización. Hecho que ha transformado al lugar de encuentro e intercambio a un intento de atractivo visual, propio de la cultura del espectáculo. Espectáculo aprovechado para el turismo y el negocio, que en el caso del pueblo, tampoco ha sido activado.
Fig. 11. Banda de Pueblo en la calle lateral del parque (Fotografía: Frantz Jaramillo).

Cabe preguntarse si esos cambios obligados del espacio han sido consensuados o discutidos con los pobladores que habitan la zona.

Cuando se iniciaron los trabajos de recuperación, los contratistas cubrieron todo el entorno del parque para que nadie pueda ver lo que ahí se hacía. Lo que no pudo ser cambiado, a pesar del ocultamiento de la obra, fue el pretil de la iglesia. El párroco puso la alerta y los habitantes, entre ellos Rex Soxa, Manuel García, y sobre todo quienes vivían cerca 
del parque lo impidieron. Esta fue la única negociación o intervención que fue permitida entre el FONSAL y los actores directamente involucrados.

Ni María ni Clara se sienten conformes con la forma actual del parque. Clara hubiera deseado que le pregunten, que alguien solicite su opinión sobre lo

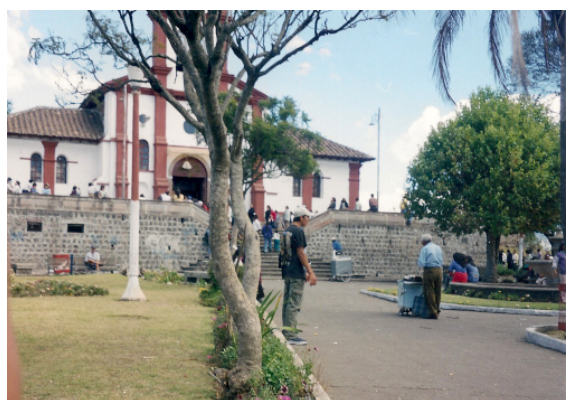

que era necesario para ella y para la gente del pueblo. María, está segura que si a ella "le hubiera tocado reconstruir el parque, lo habría hecho bien". María va más allá de la conversación e interrogando al entrevistador pregunta: " ¿A usted que le parece el parque? ¿Bonito o feo?"

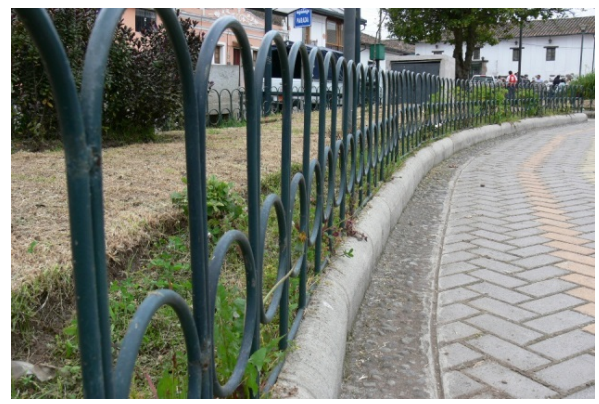

Fig. 13. Imagen del parque sin las rejas de hierro an- Fig. 14. Imagen de la formulación con rejas luego de la tes de la regeneración del FONSAL (Archivo familia intervención (foto: Frantz Jaramillo).

Veloz Santillán).

\section{CONCLUSIONES}

- El parque de Píntag ya no es un sitio de encuentro, o por lo menos, ya no tiene los usos que las personas que lo practicaban realizan en la actualidad. La plaza es ahora un lugar de tránsito destinado a la organización de sociedades disciplinadas (Foucault, 1992) para una construcción del orden de lo normal (Vila, 2014) y organizado hacia la resemantización de los usos de los espacios de la ciudad.

Quienes se servían del parque como lugar de encuentro y descanso ya no tienen esa posibilidad. Los pobladores que venían de las haciendas, como la de Valencia, Yurac, etc, descansaban en la grada de piedras 
construida sobre el desnivel del terreno y que hoy es un jardín enrejado.

- Las políticas patrimoniales intentarían una especie de limpieza sociológica y cultural de los espacios públicos, para mostrar un lugar con casas pintadas y negocios organizados dentro de las mismas edificaciones restauradas, solamente por afuera, haciendo un palimpsesto de lo que alguna vez pasó, de los espacios de memoria e intercambio social y cultural. Casos parecidos podemos hallar en todo el Ecuador, La calle la Ronda en Quito y el cerro Santa Ana en Guayaquil, por ejemplo.

- $\quad$ Sin la participación de la ciudadanía involucrada, se van desvaneciendo las prácticas populares como las festividades, negociaciones y ventas ambulantes en plena plaza (vía pública). En el caso de Píntag, el lugar de descanso de los trabajadores de hacienda, que en los años 50 libraron acaloradas disputas por obtener el derecho a las tierras prometidas por el Estado, es ahora un sitio de paso,

- La puesta en escena (Debord, 1998) nunca se desarrolló. Los negocios que prometían prosperidad, sobre todo en el campo turístico, nunca arrancaron. La pileta del parque nun- ca ha funcionado y los pobladores no se sienten a gusto con el parque:

- Pongamos que nos hubieran preguntado: señores del parque, por favor, queremos una opinión, por ejemplo. Alguien Hubiera dicho pues: no está bien o sí está bien, hubiesen dicho, pero no nos dijeron por eso es que de aquí del parque nadie está gustoso con la pila". (Clara Páez)

- Y ahora ya ve, una lástima todo, antes era más bonito, cuando no había este monte aquí". (María Maldonado)

Para las personas de la parroquia, las plantas y las flores colocadas por el FONSAL son "monte", "plantas feas", "no sirven para nada".

El espectáculo, en cuanto a los usuarios directos del espacio público hizo su debut y despedida. Al parecer, las políticas de patrimonio tienen una programación, con un mayor énfasis en el cumplimiento con los contratos y presupuestos asignados, que a realizar intervenciones que impliquen la participación de los pobladores inmediatamente involucrados. Se borran los usos prácticos de los espacios y, en su lugar se reinventan o sobreescriben, con un mismo diseño repetido en serie, entre las varias zonas urbanas o rurales de la ciudad, en lugar de la Ciudad de Quito. 
REVISTA PUCE. ISSN: 2528-8156. NÚM.104.

3 DE MAYO DE 2017 - 3 DE NOV. DE 2017, FRANTZ JARAMILLO, PP. 299-317 ו\|ll\|
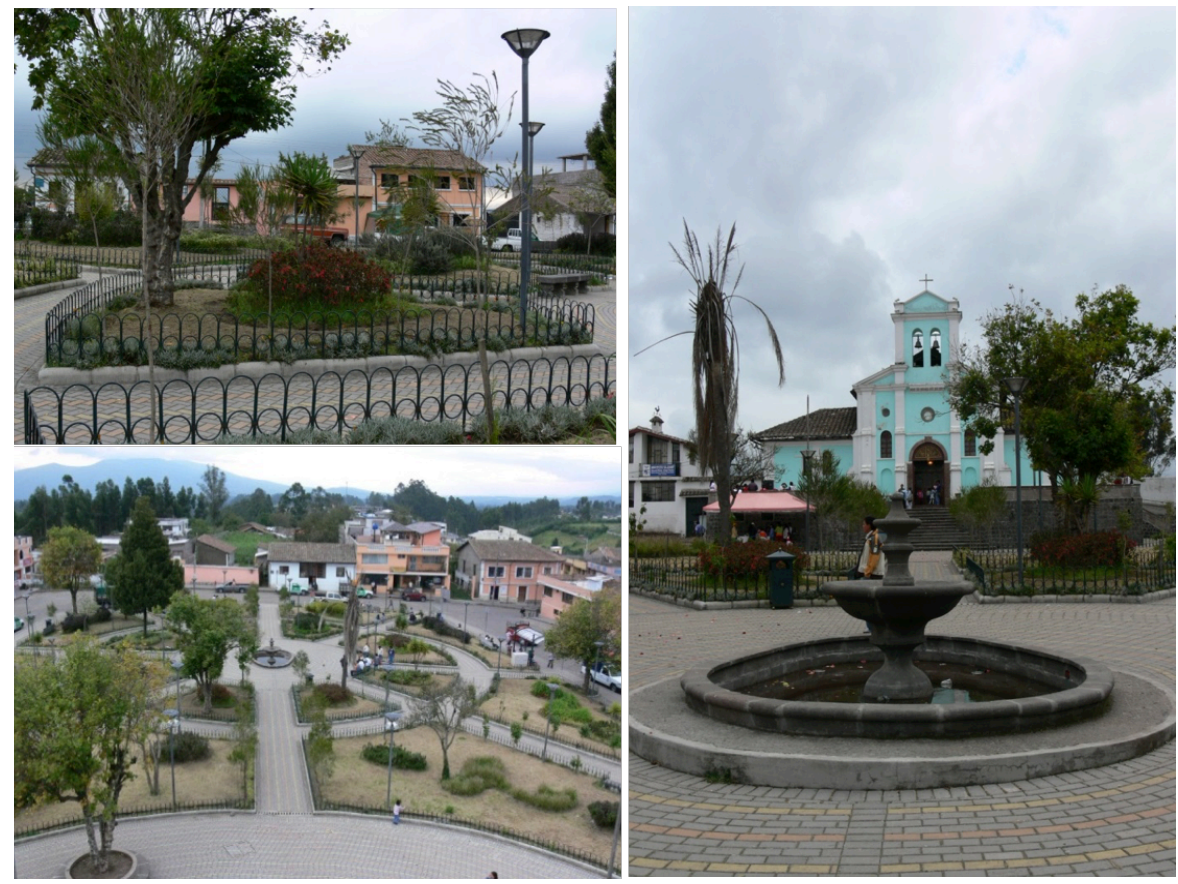

El parque de Píntag. 


\section{REFERENCIAS}

Agamben, G., (2010), Homo sacer,

Pre-Textos, Valencia, España.

Agamben, G., (1999) "Glosas marginales a los comentarios sobre la sociedad del espectáculo", en Notas sobre la política, Pre-Textos Valencia, España, pp. 68-75

Delgado M., (1999), El Animal Público, Anagrama, Barcelona, España pp. 23-58

Bourdieu, P., (1991) el sentido práctico. Taurus, pp91-111, Barcelona, España.

Buendía, A., A., \& Pino, C. J. C. (2011). Ciudad y diversidad cultural: una aproximación desde la comunicación. Revista de Ciencias Sociales. 17(1), 2011. Zulia, VE: Red Universidad del Zulia. Retrieved from http://www.ebrary.com

Cueva, S., (2010), Espacio Público y Patrimonio, análisis de las políticas de recuperación en el centro histórico de Quito, Abya Yala, Quito Ecuador.

Debord, G., (2003), La sociedad del espectáculo, Pre-Textos, Valencia, España

Foucault M., (1992) La vida de los hombres infames: ensayos sobre desviación y dominación, Madrid, La Piqueta, pp.95-17.

- (1996) Seguridad, territorio, población,
Fondo de Cultura Económica, México, pp. 15-44

- (1999) "La Gobernabilidad" en Estética, Ética y Hermenéutica. pp. 157-198 Garza, N., (2009). El espacio de la memoria. Acta Poética, Vol.30, No 2, 2009. México, D.F., MX: Red Universidad Nacional Autónoma de México. Retrieved from http:// www.ebrary.com

Gorelik, A., (1987), La grilla y el parque, Buenos Aires, Argentina

Ilg, A. (2007)., Una tesela en el mosaico urbano: Benjamín y los pasajes. Acta Poética Vol.28 No 1-2, 2007. MéxiCO, D.F., MX: Red Universidad Nacional Autónoma de México. Retrieved from http://www.ebrary. com

Kingman, E., (2004) Patrimonio, políticas de la memoria e institucionalización de la cultura, ICONOS No. 20, FLACSO ECUADOR, pp 26-34.

- (2005) Historia Urbana, orden urbano y genealogía (documento en elaboración)

Metzguer, P., et al (2016) La cuestión urbana en la Región Andina, Centro de Publicaciones PUCE, Quito, Ecuador.

Perry, F., et al, (2016) Hábitats justos, diversos y sustentables, FES/ILDIS, Quito, Ecuador. 
Richard, N., (2007), Fracturas de la memoria, Siglo XXI, Buenos Aires, Argentina. pp79-92

Sierra, F., et al (2016) Comunicación y Ciudad, la mediación social en la nueva era urbana, Gedisa, Barcelona, España.

Sosa, R., (1996) Miscelánea Histórica de Pintag, Abya Yala, Quito Ecuador.

Ayala, Ma., (2006), Revista de la Escuela de Arquitectura de la Universidad de Costa Rica -UCR - Volúmen 2
-1 del 2013 - Número 03 - ISSN 2215-275X, http://revistas.ucr.ac. $\mathrm{cr} /$ index.php/revistarquis/article/ viewFile/8621/8150

Vila, D., (2014), La gobernabilidad más allá de Foucault. Prensas de la Universidad de Zaragoza, Zaragoza, España. 
